\title{
Research Gate (RG) is a Meeting Point for Progress in Chemical Knowledge
}

\author{
Ilia Brondz \\ Norwegian Drug Control and Drug Discovery Institute (NDCDDI) AS, Ski, Norway \\ Email: ilia.brondz@gmail.com
}

How to cite this paper: Brondz, I. (2019) Research Gate (RG) is a Meeting Point for Progress in Chemical Knowledge. International Journal of Analytical Mass Spectrometry and Chromatography, 7, 35-36. https://doi.org10.4236/ijamsc.2019.73004

Received: August 30, 2019

Accepted: September 27, 2019

Published: September 30, 2019

Copyright $\odot 2019$ by author(s) and Scientific Research Publishing Inc. This work is licensed under the Creative Commons Attribution International License (CC BY 4.0).

http://creativecommons.org/licenses/by/4.0/ c) (i) Open Access

\begin{abstract}
Chemistry is one of the eldest and basic sciences. The technological progress is depending on progress in chemistry. Without evaluation of nature and preparation of a pure substance, it is not imaginable existence of modern biology, medicine, metallurgy and physics. All kind of existing technologies needs distinct in nature and pure in quality substances for existence and further progress. RG aims to bring together leading academic scientists, researchers and research scholars to exchange and share their experiences and research results on all aspects of chemistry and related fields. It also provides an interdisciplinary platform for researchers, practitioners and educators to present and discuss the most recent innovations, trends, and concerns as well as practical challenges encountered, and solutions adopted in the fields of chemistry. One of the nearly developed concepts in liquid chromatography is described in [1], which is a new type of liquid chromatography, the new technology as the Colloidal High-Performance Liquid Chromatography (CHPLC). This type of new technological approach in high-performance liquid chromatography is a simple time- and labor-saving one-step procedure suitable for analytical-, semipreparative-, and preparative-scale preparation of bacteriocins and other cationic antibacterial peptides as well as other cationic small molecular weight species. It allows to suspensions of bacterial cells, other colloidal and fast-particle materials, and dissolved anionic molecules passed through the column; however, cationic bacteriocins, small cationic peptides, organic cationic molecules and metal cations were separated by chromatography. The purity of the target substance generally at more than $95 \%$ was achieved by the judgment of spectral, chromatographic, and antimicrobial activity. In [1] was described the preparation, purification and chromatography of bacteriocin, bacitracin and lysozyme. It is my pleasure to invite all the great scientists, academicians, young researchers, students and everyone who is interested in Science, especially in chemistry from all over the world to attend the RG. All who are interested in theoretical and applicational aspects in
\end{abstract}


Chemistry, New Materials Research and Nanotechnology will find them in RG. The topics as: Organic Chemistry and Advances in Organic Chemistry, Analytical Chemistry, Medicinal Chemistry, Clinical Chemistry, Forensic Chemistry, Industrial Chemistry and Occupational Chemistry, Food Chemistry, Green Chemistry and Chemical Renewable Resources, Agricultural and Food Chemistry, Physical and Theoretical Chemistry, Biological Chemistry, Marine Chemistry, Inorganic Chemistry, Environmental Chemistry, Nanoscience and Technology, Polymer Chemistry, Material Chemistry, Natural Resources Chemistry and Natural Products Chemistry, Electrochemistry, Geochemistry, Radio and Nuclear chemistry, Physical Chemistry, Theoretical Chemistry, Space (Interplanetary) Chemistry and many more are present on the pages of RG. At RG you will find the state-of-the-art research and cutting-edge theoretical and applicational technologies. The RG is covering a number of global aspects in Chemistry, New Materials Science and Nanotechnology from purely fundamental research up to practical applications.

\section{Keywords}

Research Gate (RG), Chemistry, Knowledge

\section{Conflicts of Interest}

The authors declare no conflicts of interest regarding the publication of this paper.

\section{References}

[1] Brondz, I. (2018) One-Step Procedure for Direct Purification of Pediocin-Like Bacteriocins and Cationic Antimicrobial Peptides from Complex Culture Medium on an Analytical, Semipreparative, and Preparative Scale. A New Type of Liquid Chromatography-Colloidal High-Performance Liquid Chromatography (CHPLC). International Journal of Analytical Mass Spectrometry and Chromatography, 6, 41-49. https://doi.org/10.4236/ijamsc.2018.63004 